\title{
Study of Spider Silk Fibers by Raman Microscopy
}

\section{Maria Fernanda Vargas-Charry, Carlos Vargas-Hernández ${ }^{*}$}

Laboratorio de Propiedades Opticas de Materiales (POM), Universidad Nacional de Colombia sede Manizales, Manizales-Caldas, Colombia

Email: *cvargash@unal.edu.co

How to cite this paper: Vargas-Charry, M.F. and Vargas-Hernández, C. (2018) Study of Spider Silk Fibers by Raman Microscopy. American Journal of Analytical Chemistry, 9, 529-545.

https://doi.org/10.4236/ajac.2018.910039

Received: August 22, 2018

Accepted: October 26, 2018

Published: October 29, 2018

Copyright ( 92018 by authors and Scientific Research Publishing Inc. This work is licensed under the Creative Commons Attribution International License (CC BY 4.0).

http://creativecommons.org/licenses/by/4.0/

(c) (i) Open Access

\begin{abstract}
Spider silk fibers of species of the genera Araneus, Gasteracantha, and Linothele sericata were studied. The fibers are composed of axial threads and lateral villi, allowing adhesion to surfaces. Raman spectroscopy was used to determine the surface and internal composition of the threads forming the structure. In the three species, the characteristic amino acid peaks of the spider web were found between 2871 and $2975 \mathrm{~cm}^{-1}$, which belong to L-glycine, L-alanine, L-glutamine, and L-proline. The threads are composed of a protective layer mainly composed of amides, alanine, and glycine. The fibrils surrounding the axial fibers consist mainly of amide II $\left(1533 \mathrm{~cm}^{-1}\right)$, which allows adhesion between the thread and the surfaces onto which the spider weaves the web. For the genus Linothele sericata, there is a peak on the surface of this spider web located at $2145 \mathrm{~cm}^{-1}$, which is associated with isonitriles with R-N-C bonds.
\end{abstract}

\section{Keywords}

Spider Silk Fibers, Raman Spectroscopy

\section{Introduction}

The first uses of spider webs in medicine date as far back as the ancient Greeks, who used this material as healing bands; webs were used to cover severe bleeding and protect wounds from infections because the material was thought to have the ability to keep injuries clean [1]; furthermore, spider web fibers are stronger than steel, have substantial flexibility and elasticity, are thinner than a human hair, and are biodegradable. Today, spider silk is used as a replacement for muscles and ligaments in the human body.

Spider webs are formed from an organic biomolecule that consists essentially 
entirely of oxygen, carbon, hydrogen, and nitrogen. The evolutionary process of spider species has involved biochemical developments, which have allowed the tissues to change their properties. These changes have been observed by comparing the amounts of amino acids present in silks of different species. It is known that the percentages of glycine and alanine are maintained; however, other amino acids, such as D-proline, serine, tyrosine, and glutamine appear in different amounts; in some cases, carbohydrates, lipids, ionic compounds, and certain pigments are also found. Peptide bonds arise from the linkage of amino acids, giving rise to proteins, which in this case are referred to as spindroins. To date, only two classes of these proteins have been identified [2]: spindroin-1 and spindroin-2.

The chemical composition of a spider web is characterized by three structural levels:

Primary structure: This structure is based on the specific polypeptide sequence of each protein, where peptide bonds are responsible for the linkage of the amino acids; overall, in this structure, the sequence consists of alanine and glycine.

Secondary structure: The polypeptide chains occupy spatial conformations arising from the various blocks of amino acids present in the formation of the spider web; however, these structures change depending on the type of amino acid that predominates: if the chain is very rich in alanine, its secondary structure is $\beta$-sheet-type, thereby forming regular crystalline blocks, whereas proteins in which glycine predominates have an amorphous structure accompanied by $\alpha$-helical structures.

Tertiary structure: This structure describes the way in which secondary substructures are arranged and interact. It is believed that the arrangement of these structures provides the favorable mechanical properties of the spider web [3] [4].

The properties of spider webs are numerous due to the features mentioned above. The fibers are characterized by nonlinear elastic behavior, so that small deformations are proportional to the force exerted, but once the fiber passes a deformation threshold, the material becomes much stiffer [5] [6]. This material is constructed through protein synthesis, and the combined proteins give rise to the primary and secondary structures, which together form a structure as strong as steel (up to seven times greater than steel) but that can undergo strains as large as those in rubber. Furthermore, this silk is biodegradable and has the ability to retain large water quantities, thus modifying its structure. Notably, the properties of this fiber have not yet been fully surpassed by any synthetic fiber, but its already existing properties have produced very efficient results in their fields of application.

The mechanical properties of spider webs vary depending on the species, as these adapt to the climatic, hunting, and survival needs of each genus [7]. Here, we focus on several species to perform comparisons with the data found in the literature on different species to examine which type of silk has better mechanical properties. Spider silk is a material with great toughness, as it is one of the 
few materials, if not the only material, that has the advantage of being very resistant to breakage and simultaneous very stretchable; it should be noted that when it is said that the spider web is stronger than steel, this statement takes into account the differences in densities between both materials and assuming similar dimensions. In this regard, spider silk is up to seven times stronger than steel, and its deformation capacity is ten times greater; therefore, we can conclude that this is one of the materials with the greatest toughness yet found [8].

Organic materials generally exhibit unfavorably low thermal and electrical conductivity; however, spider silk is once again an exception, as the results demonstrate that it is a high conductivity material.

Currently, the use of biomaterials is well established in the fields of bioengineering and nanotechnology because these materials have important characteristics that can help improve the physical and chemical properties of existing materials. Moreover, certain processes can be applied to materials to enable them to serve as a structure that complements regenerating tissues without certain disadvantages [9], or in a matrix form with desirable properties that can meet application constraints that would otherwise require material replacement. Because of these reasons, we have investigated the spider web, which is a very common biomaterial in nature, not highly valued, and present in the waste of most homes in the world. This is a material that has unique structural properties and can be used as a reference for structural modifications to existing materials [10]. Because of the physical and chemical properties found in this biomaterial, many researchers are conducting studies on combining biomaterials and existing materials in order to establish a synergy between them.

Spiders belong to the taxonomic order Araneae, which in turn comprises two suborders, Orthognatha and Labidognatha, which are differentiated by evolutionary, morphological, ecological, and behavioral characteristics [11]. The order Araneae is the most diversified group of land predators; approximately 41,250 species are currently known [12], most of which use silk fundamentally for their survival and success ("fitness") [13], as it is used for the construction of traps and shelters, egg protection (cocoons), draglines, and reproduction and as physical support during communication between the spider and food [11]. Within the suborder Labidognatha, one of the best known and largest families is Araneidae [14], which has a cosmopolitan distribution, with more than 160 genera and 2800 species; this diverse group occupies a wide range of habitats and belongs to the group of orb-web-builder spiders, which use a sticky spiral web to captureprey [15] (Image 1). They are euryphagous predators (i.e., they consume a wide range of prey), build their web in vegetation, and can exhibit diurnal or nocturnal activity depending on the species [16]. Some species of Araneidae build visually striking bands or tufts of white silk, known as stabilimenta, which are conjectured to perform functions such as attraction of prey, physical reinforcement of the web, camouflage against predators, warning (to prevent large animals causing damage to the spider web), and UV reflectance [17] [18]. 


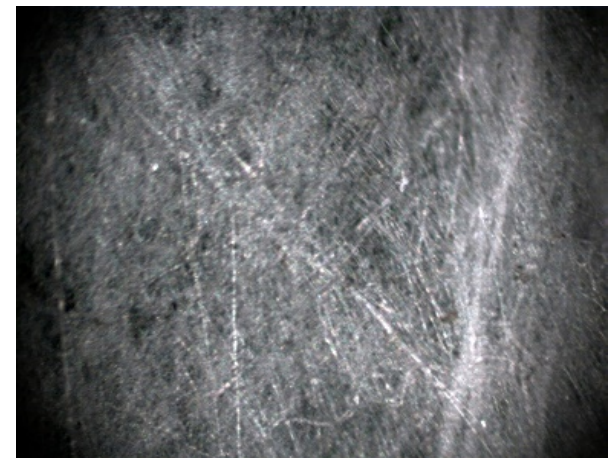

Image 1. Spider silk fibers of the genus Araneus taken at 10× magnification.

The genus Araneus belongs to the family Araneidae, they are spiders that build, at one end of the web, a conical shelter consisting of a folded green plant leaf, lined with silk, and sometimes with stabilimenta; the shelter is connected to the center of the web by a thread held by one or more legs of the spider, which rests in the shelter and becomes activated when it senses the vibrations of possible prey in the sticky spiral [18].

The genus Gasteracantha comprises spiders known as "orb-web spiders with spined opisthosoma"; they belong to the family Araneidae and exhibit bright colors that are hypothesized to be related to attracting prey. Their orb webs are built in open and relatively large places, with anchor lines that extend from 2 to $4 \mathrm{~m}$ from the support area; the sticky spiral can have a diameter of $0.6 \mathrm{~m}$. Some species, such as Gasteracantha cancriformis, which are distributed in the new world, have spider webs with very particular stabilimenta, consisting of white silk "tufts" located at the web's outer rim and anchor lines, which are thought to serve the function of warning large animals, so these do not cause mechanical damage to the spider web [19] [20] [21].

The suborder Orthognatha includes spiders living in silk-lined shelters, on the ground, under rocks, or in roots; the entrance to the shelters is opened or closed with a small trapdoor of silk or debris; and most species exhibit nocturnal activity [22]. The family Dipluridae belongs to the suborder Orthognatha; the species live in silk-lined shelters built in cracks and extending outwards in the shape of a funnel, forming a web shaped like a leaf or irregular lamina; the vibrations of animals (possible prey) walking down the spider web can be perceived by the spider [15] [22].

The spider web is a mechanically robust material for two reasons: the first is that its threads combine resistance to stress at the breaking point with ductility, and the second is that the architecture and design of the spider webs gives rise to a structure capable of absorbing large impacts [23]. Silks generally tend to break depending on the shape of the animal habitat, and in the case of spiders that weave irregular spider webs, their spider webs break into lengths of approximately $20 \%$ or $35 \%$ of the total initial length. In contrast, in spiders that weave spiral silks, their spider webs present deformations in their length ranging between $60 \%$ and $180 \%$ of their total length, and even $270 \%$ in some cases, as is the 
case in Araneus diadematus [24]. The toughness varies depending on the species; for example, in silk weaved by the species ampulácea mayor, the toughness is approximately $138 \mathrm{MJ} \cdot \mathrm{m}^{-3}$, and in the silk of Hyptiotes cavatus [23], it is approximately $164 \mathrm{MJ} \cdot \mathrm{m}^{-3}$. The stiffness of this type of biomaterials belonging to species such as ampulácea mayor is 3 to $10 \mathrm{GPa}$, which is smaller than materials such as steel or Kevlar but far superior to most polymeric materials [14] (see Table 1). Likewise, the elastic limit varies by species; however, this is usually approximately $3 \%-5 \%$ in terms of deformation and 200 to $800 \mathrm{MPa}$ in terms of tension [20]. The tensile strength varies with the weaving speed and is usually between 0.6 and $1.5 \mathrm{GPa}$ [25].

Currently, spider silk is eagerly being investigated, as it is a material offering advantageous physical and biological properties. For example, in Germany, there are efforts to develop artificial threads to manufacture a biomimetic weaving device [26]. Spider silk has also served as a design model for architectural structures, in the field of medicine as a model in sutures and tissue regeneration, and in industry to make bullet-proof vests. Many other uses likely await discovery.

These beneficial properties motivated us to dedicate ourselves to the study of the material to obtain even more detailed information, such as the chemical composition and microscopic organization of the structure. Thus, we decided to investigate the structural, chemical, and physical conformation of spider webs of the genera Araneus, Gasteracantha, and Linothele sericata, which are located in the coffee region of Colombia and especially around the city of Manizales. Spider web is a material with exceptional mechanical properties among many other natural and artificial materials because its strength is five times greater than steel and three times greater than some artificial fibers; it is also very light, as each fiber can measure approximately $3 \mu \mathrm{m}$ in diameter [27].

Table 1. Comparison of tensile strength and elongation in various materials.

\begin{tabular}{ccc}
\hline & Tensile strength (MPa) & Elongation (\%) \\
\hline Skin & 50 & 75 \\
Kevlar & 3000 & 3 \\
Rubber & 30 & 600 \\
Silicone & 5.5 & 530 \\
Crystal & 403 & 0 \\
Ceramics & 241 & 0 \\
Brass & 530 & 5 \\
Steel 316 L & 620 & 51 \\
Cobalt & 820 & 18 \\
Bronze & 700 & 11 \\
Titanium (Grade 2) & 2490 & 26 \\
Spider web & 600 & 270 \\
\hline
\end{tabular}




\section{Materials and Methods}

Material selection was performed by taking three fibers from each of the species (Araneus, Gasteracantha, and Linothele sericata); these fibers were taken from the botanical garden of the University of Caldas (Manizales), located in the Andean region of Colombia, and under the following conditions: $8 \mathrm{~K}$ representative ecosystem, temperate rainforest; temperature, $14^{\circ} \mathrm{C}$; altitude, $2160 \mathrm{~m}$ above sea level; and relative humidity, $77 \%$. Spider silk was collected using disinfected forceps and was individually packaged in sealed plastic bags to avoid contamination as much as possible; the bags were labeled with the genus of each species and the temperature and humidity conditions upon collection. The fibers were then studied by confocal microscopy and Raman spectroscopy to obtain detailed information on the morphological structure of the webs and the chemical and structural composition of the fibers.

Raman spectroscopy is a technique used to study the normal modes of oscillation of the chemical structures that compose materials; vibrational and rotational modes are found within the frequencies. The technique uses lasers, which are generally in the range of visible light, near-infrared, or ultraviolet. The light interacts with the sample through inelastic interaction and generates phonons that cause the energy of the incident photon laser to move up or down the electromagnetic spectrum. Due to the emission of elastic Rayleigh scattering, wavelengths near the laser line are filtered, while the rest of the light is collected onto a detector [28]. Vibrational analysis was achieved through Raman spectroscopy using a confocal high-resolution LabRamHR Horiba Jobin Yvon microscope with $473 \mathrm{~nm}$ DPSS laser line excitation and a power $<50 \mathrm{~mW}$. The laser spot was focused on the sample using Olympus $\times 10, \times 50$, and $\times 100$ objectives.

\section{Results and Discussion}

\subsection{Genus Araneus}

In this genus, the spider web contains threads in different directions without preferential order (Image 1, 10x). When the sample is magnified (Image 2, 50x) and the focus is on one of the fibers, small hairs are evident on each of these fibers. The fibers are $20 \mu \mathrm{m}$ thick and are composed of axial threads with an approximate size of $1 \mu \mathrm{m}$. When the $100 \times$ objective is used (Image 3 ), a loss of the protective thread cover is observed, given that the power incident on the thread under these conditions is approximately $20 \mathrm{~mW}$; this covering is mainly composed of amides $\left(1245 \mathrm{~cm}^{-1}\right)$, alanine $\left(1456 \mathrm{~cm}^{-1}\right)$, and glycine $\left(2882 \mathrm{~cm}^{-1}\right)$, see Figure 1.

Figure 1 shows the characteristic peaks located between 1245 and $2975 \mathrm{~cm}^{-1}$, which correspond to the basic compounds of spider silk, including the amino acids glycine, alanine, L-glutamine and L-proline; the position of the peaks and their specific attributions are shown in Table 2.

When the power exceeds $20 \mathrm{~mW}$, the cover of the silk threads evaporates due to the laser (see Image 3), revealing a uniform cylindrical thread formed mainly 
by L-alanine, L-glutamine, and L-proline.

Image 4 shows the spider web threads of the genus Araneus, but in this case, the fiber was on a plant leaf where the spider had weaved its nest; two thick silk threads can be observed that are composed of several fibrils united by tufts located at intervals of approximately $5 \mu \mathrm{m}$; these allow the structure of the silk web to be resistant to compression as well as to tensile stress.

Table 3 shows the assigned peaks according to the Raman spectra (Figure 2) obtained from different regions of the thread. The spectrum taken at the junction between the thread and the plant leaf shows a peak of great intensity associated with amide II $\left(1533 \mathrm{~cm}^{-1}\right)$; this finding indicates that the amide constitutes part of the thread cover, which allows adhesion between the thread and those surfaces onto which the spider weaves the web.

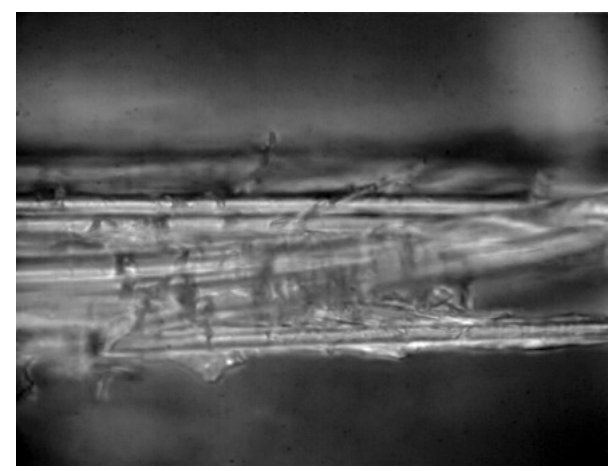

Image 2. Spider silk fibers of the genus Araneus shown at 50× magnification.

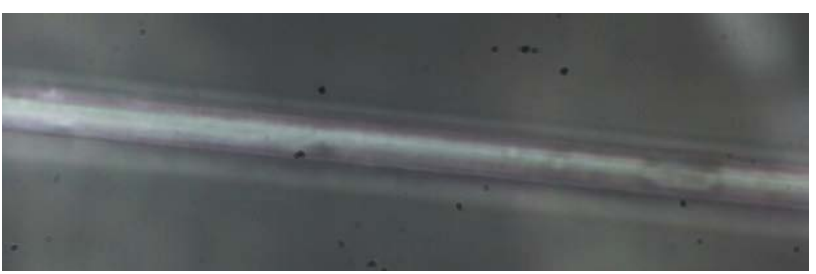

(a)

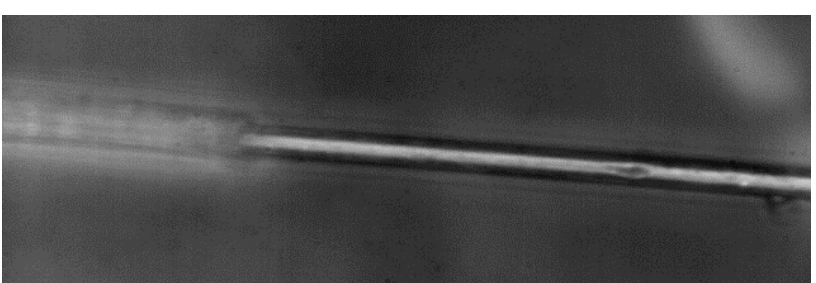

(b)

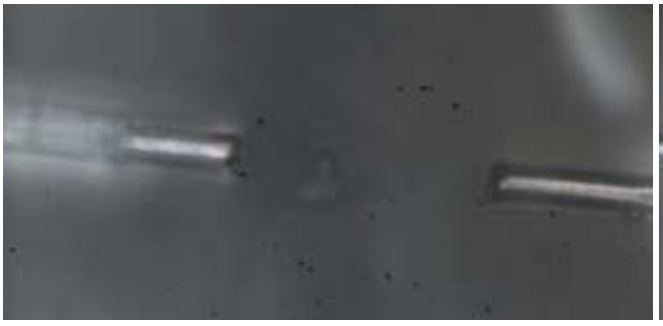

(c)

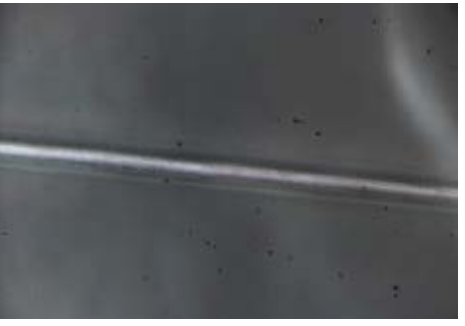

(d) 


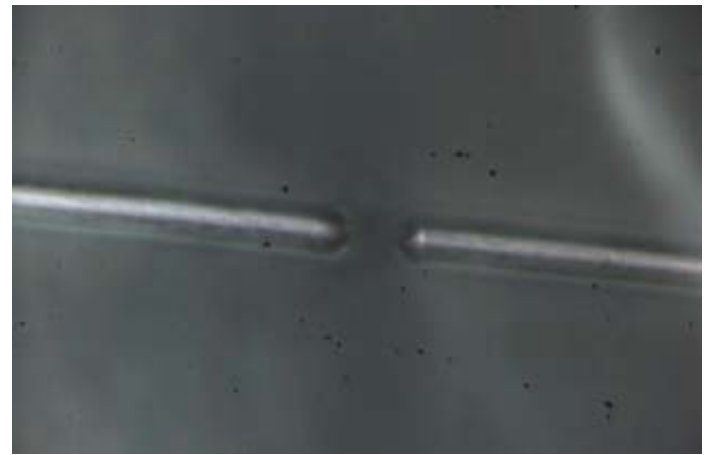

(e)

Image 3. (a), (b), (c), (d) and (e). Spider silk fibers of the genus Araneus shown at $100 \times$ magnification. In this case the power laser produce.

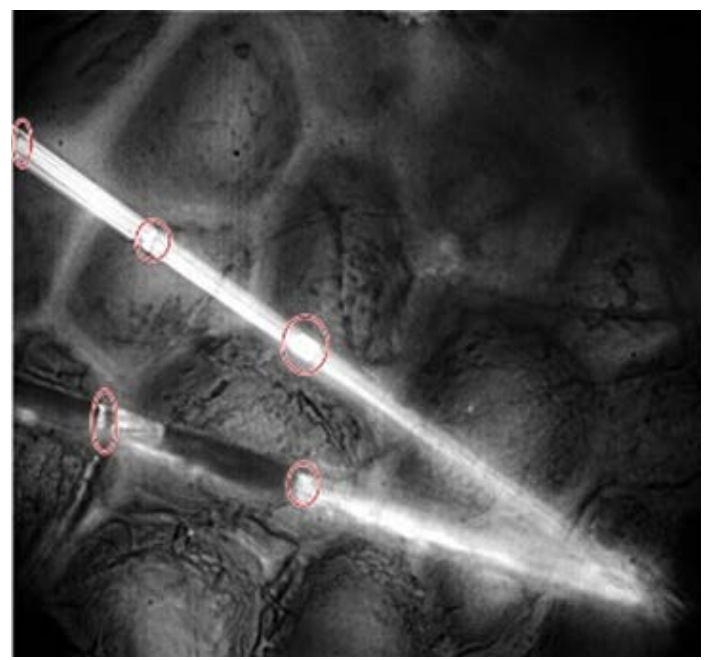

Image 4. Spider silk fibers of the genus Araneus taken on a plant leaf (50×).

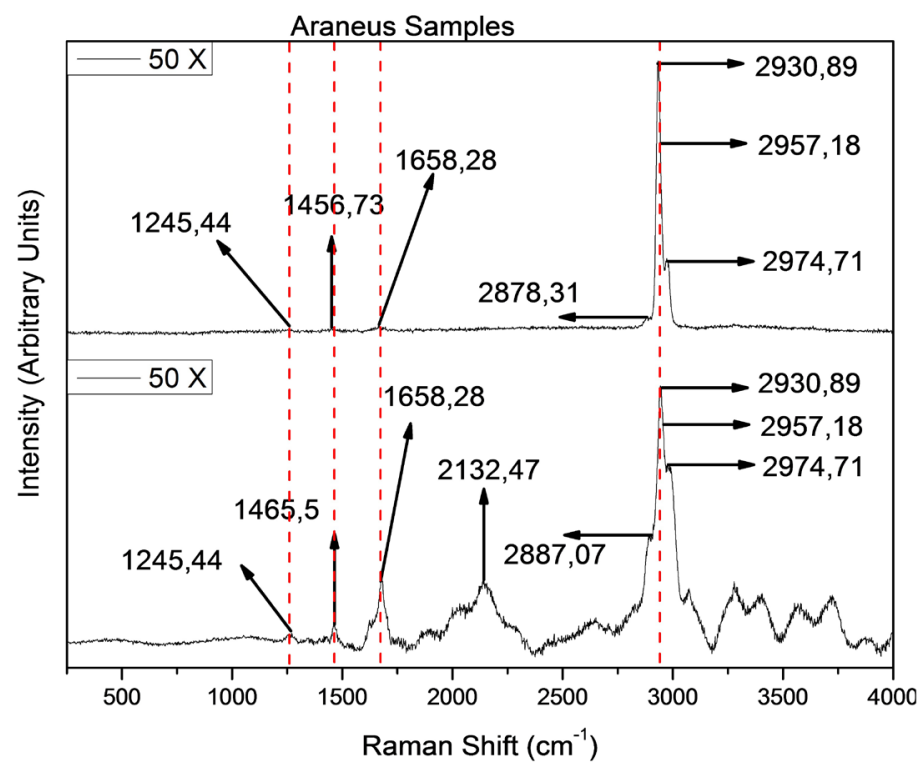

Figure 1. Raman spectra of a spider web fiber of the genus Araneus at $10 \times$ and $50 \times$ magnification. 


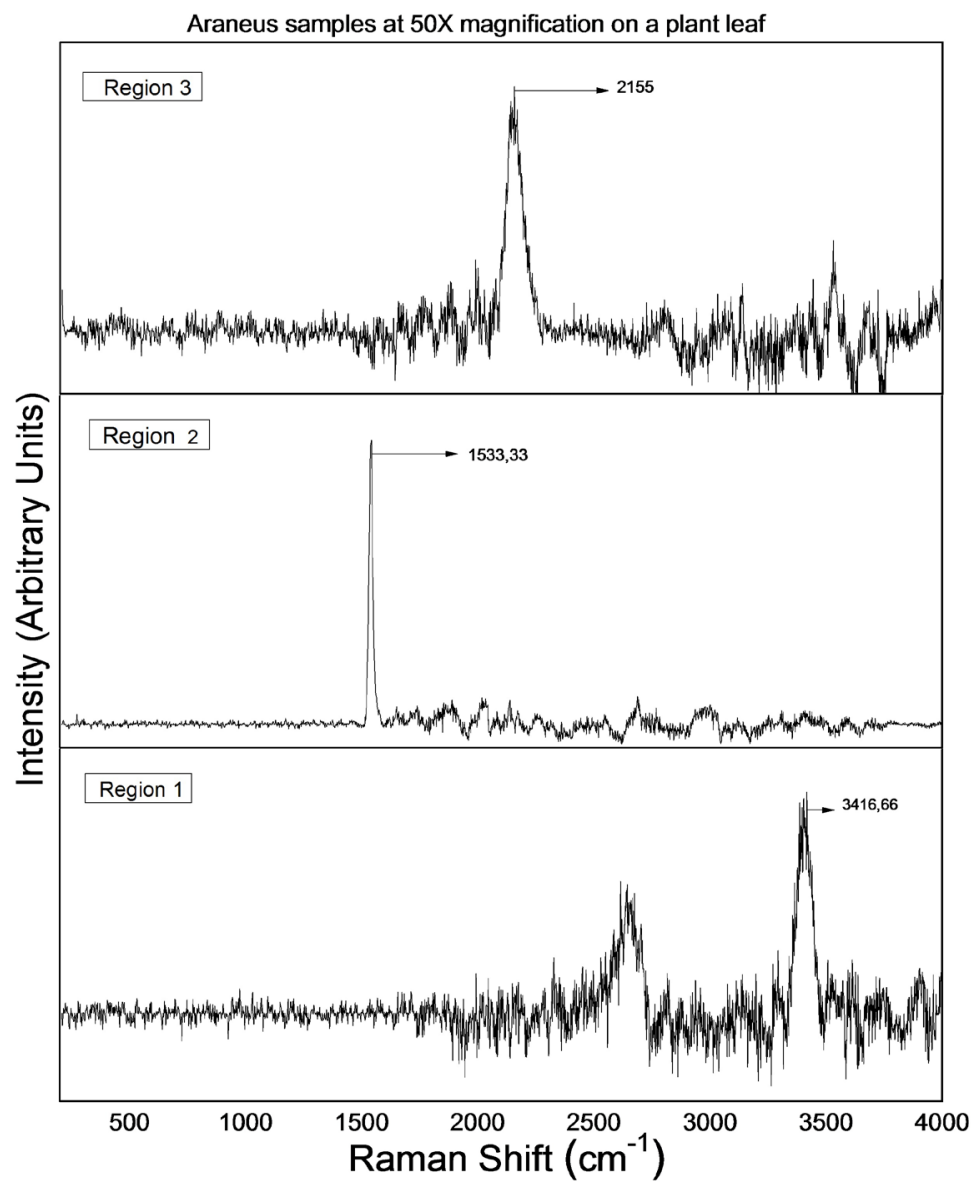

Figure 2. Raman spectra of a spider web fiber of the genus Araneus, fixed on a plant leaf, at $50 \times$ magnification.

Table 2. Composition of the spider web of the genus Araneus.

\begin{tabular}{cc}
\hline Raman Shift $\left(\mathrm{cm}^{-1}\right)$ & Attributions \\
\hline 1245.44 & Amide II \\
$1456.73-1465.5$ & Alanine \\
1658.28 & Glycine \\
2132.47 & Isonitrile R-N-C bond \\
2882.10 & L-glycine \\
2936.84 & L-alanine \\
2955.65 & L-glutamine \\
2974.47 & L-proline \\
\hline
\end{tabular}

Table 3. Composition of the spider web of the genus Araneus, fixed on a plant leaf.

\begin{tabular}{cc}
\hline Raman Shift $\left(\mathrm{cm}^{-1}\right)$ & Attributions \\
\hline 1533.33 & Amide II \\
2155 & Isonitrile R-N-C bond \\
3416.67 & Amide A
\end{tabular}




\subsection{Genus Gasteracantha}

For the genus Gasteracantha, we gathered two collections of silk; the first sample was measured four times with two different objectives, one at $10 \times$ and another at 100× magnification, and Images 5-7 shows that the spider silk or web is not made only by a thin thread but by a thread that contains a cover from which small fibers emerge and whose function is to adhere to surfaces. This internal thread is shown when the laser power exceeds $20 \mathrm{~mW}$, which induces the evaporation of the elastic silk cover.

Figure 3 shows the peaks obtained, which are characteristic of the predominant amino acids in the spider web, located between 2871 and $2975 \mathrm{~cm}^{-1}$ (Table 3). In this particular case, the measurement of the surface fiber lacks certain elements that appear on the inside of the spider silk fibers, such as L-glycine, which is responsible for synthesizing substances.

In the second sample (Image 5), a measure was taken at 50× magnification. Anaccumulation of silk is observed; this accumulation of silk is used as a protective mechanism by the spider. Peaks are evident between 1257.09 and $2975 \mathrm{~cm}^{-1}$ (Figure 4), which belong to the amino acids present in the silk and other compounds, described in greater detail in Table 4. Image 6 shows branching smaller fibers, which adhere to vegetation through fibers of larger diameter.

\subsection{Genus Linothele sericata}

In the analysis of the fiber, Image 8 and Image 9 show that this type of silk is hairy or fibrous and has a rather irregular formation because such structures or spider webs are constructed in shelters created close to the ground; a large number of hairs in each of their threads results in the prey adhering easily to the spider web.

For this species, we conducted an analysis of the spider web at $10 \times$ (Figure 5) and 50× magnification (Image 9 and Image 10), preventing fiber degradation due to the high power laser. At $10 \times$ magnification, a single peak is observed located at $2145 \mathrm{~cm}^{-1}$, associated with isonitriles with R-N-C bonds arising outside of the fiber. At 50x magnification, corresponding to a power of approximately $15 \mathrm{~mW}$, other peaks are evident that are characteristic of spider silk (Figure 4 and Table 5 for genus Gasteracantha and Figure 5 and Table 6 for genus Linothele sericata); these are due to the increased Raman efficiency obtained from increasing the laser power.

Image 10 shows the spider web of the genus Linothele sericata at 100X with a cover of thin axial fibers that bind other larger diameter fibers, forming a complex structure.

\section{Conclusions}

The characteristic peaks of the amino acids of the spider web are found between 2871 and $2975 \mathrm{~cm}^{-1}$, and they belong to L-glycine, L-alanine, L-glutamine, and L-proline. By analyzing the images, it was observed that spider silk is not composed 
of a single thread but of several threads with different thicknesses and axial winding, and this large fiber has large villi that favor surface adhesion. According
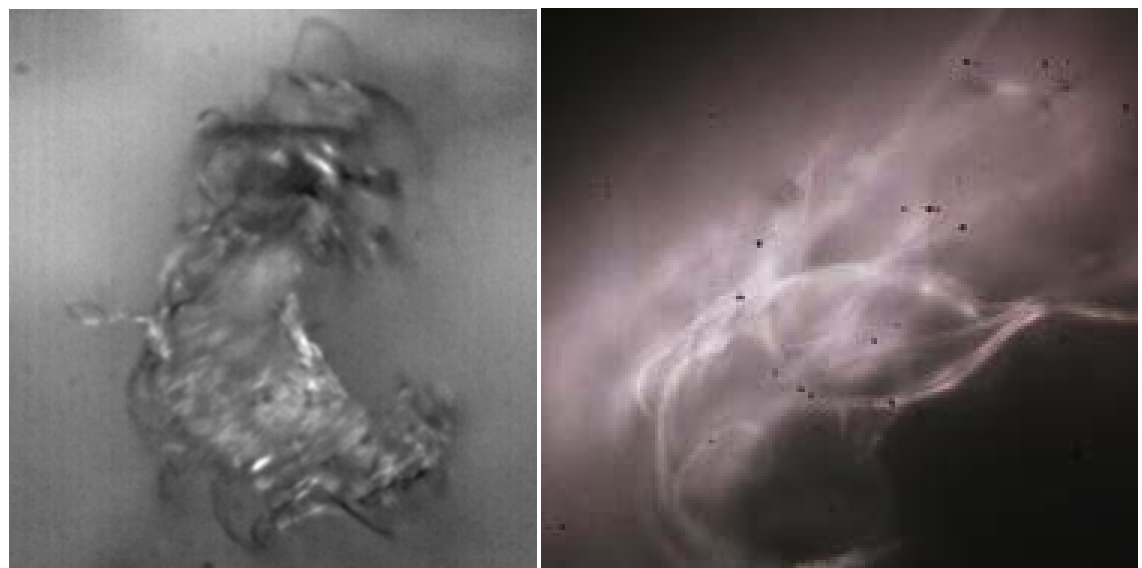

Image 5. Spider web fiber of the genus Gasteracantha at 10× and 100× magnification.

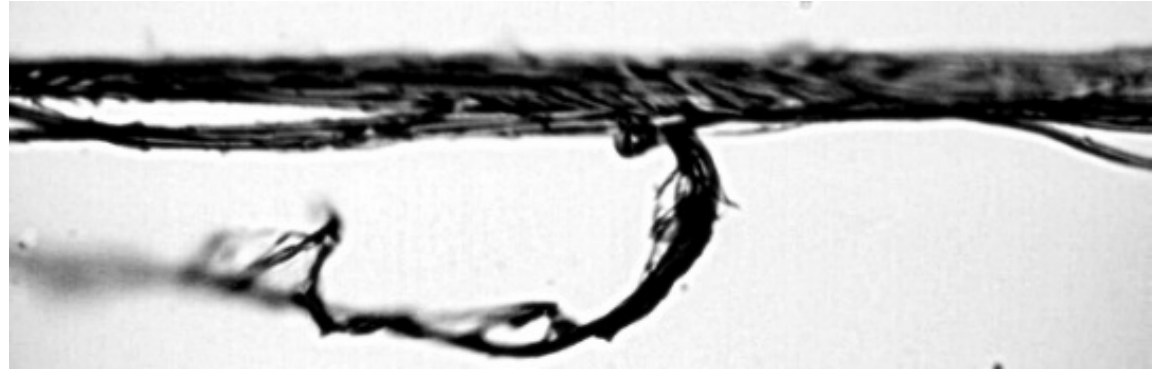

Image 6. Spider web of the genus Gasteracantha at 100× magnification.

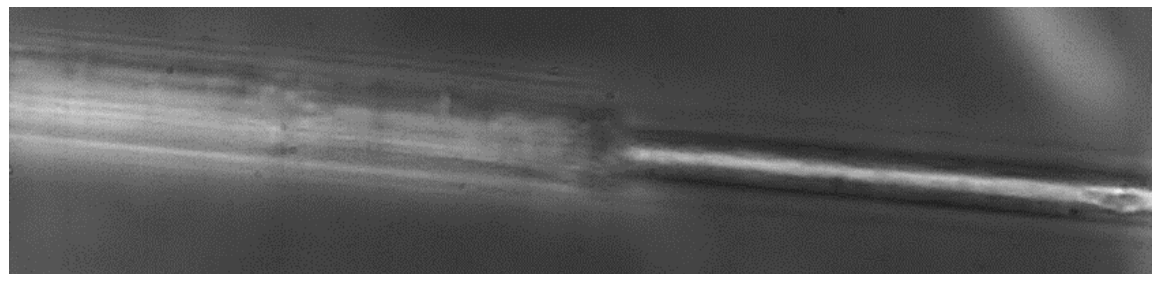

Image 7. Spider silk fibers of the genus Gasteracantha taken at 100× magnification.

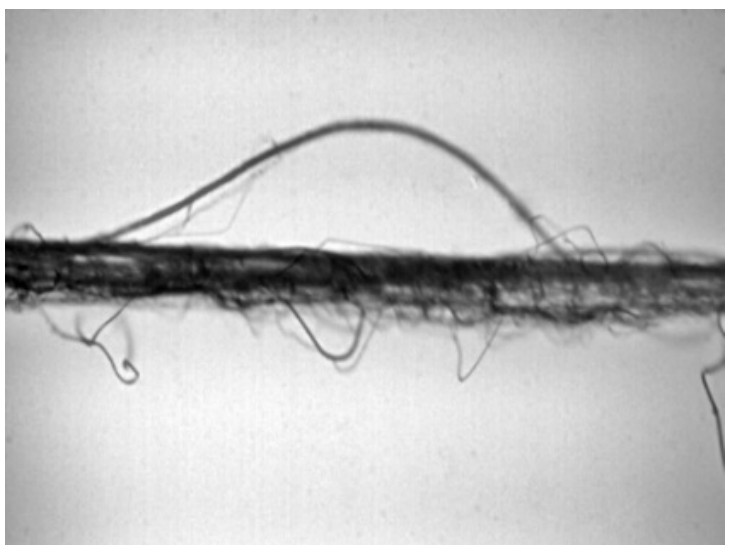

Image 8. Spider web fiber of the genus Linothele sericata a $10 \times$ objective. 


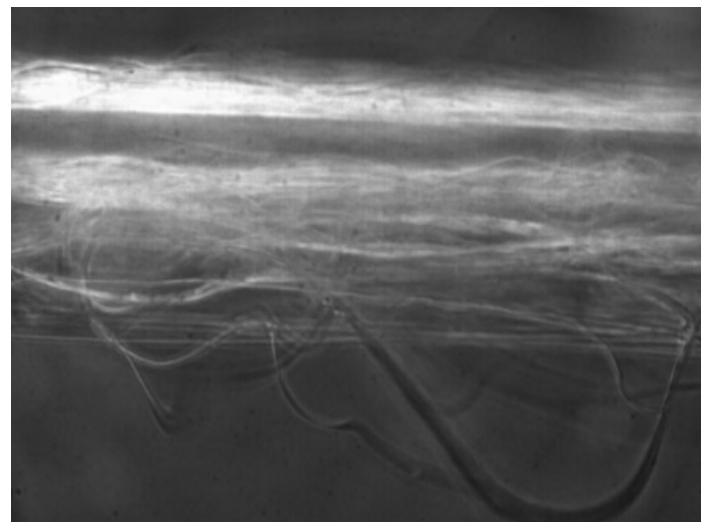

Image 9. Spider web fiber of the genus Linothele sericata at $50 \times$ magnification.

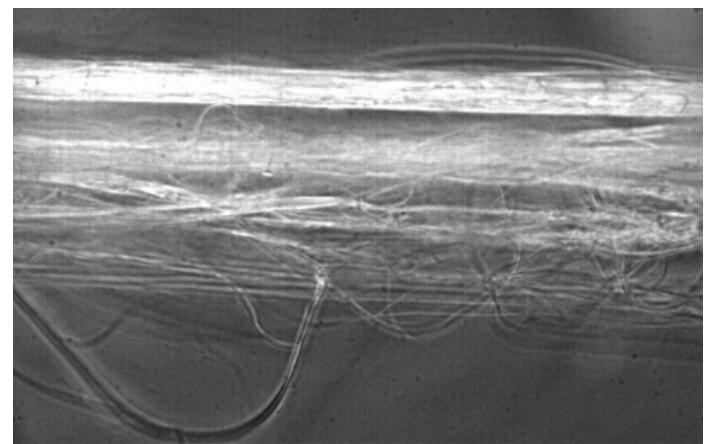

Image 10. Spider web of the genus Linothele sericata at 50× magnification.

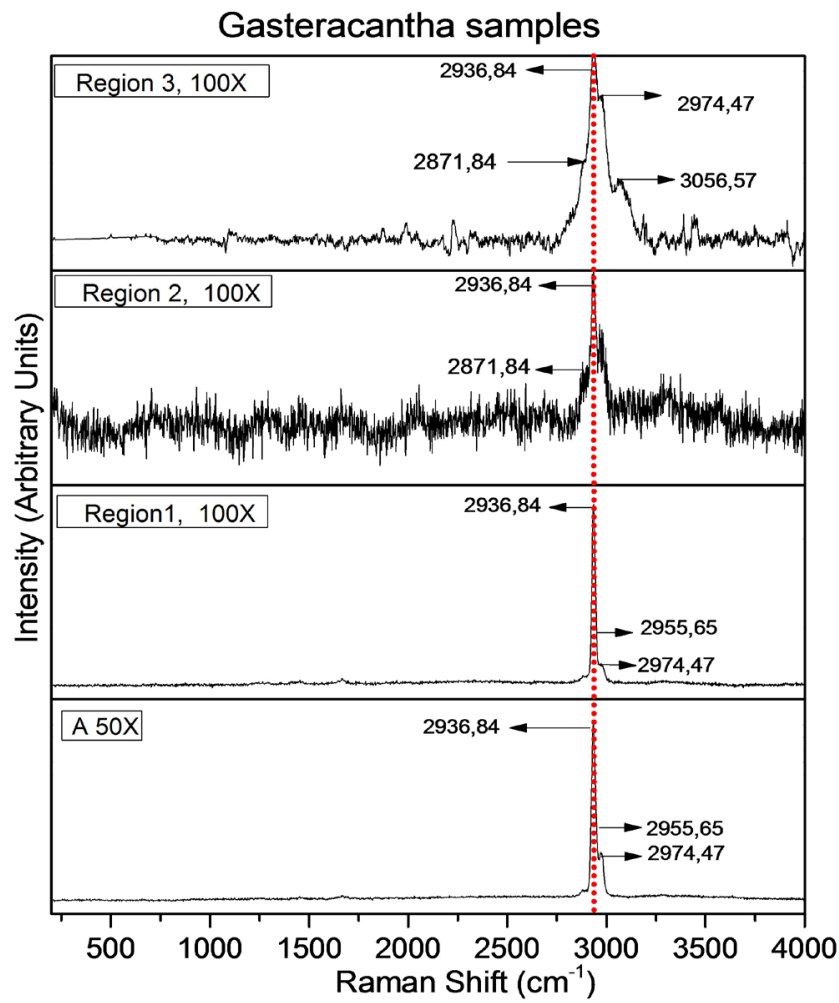

Figure 3. Raman spectra of the spider silk fiber of the genus Gasteracantha at $100 \times$ and $50 \times$ magnification. 


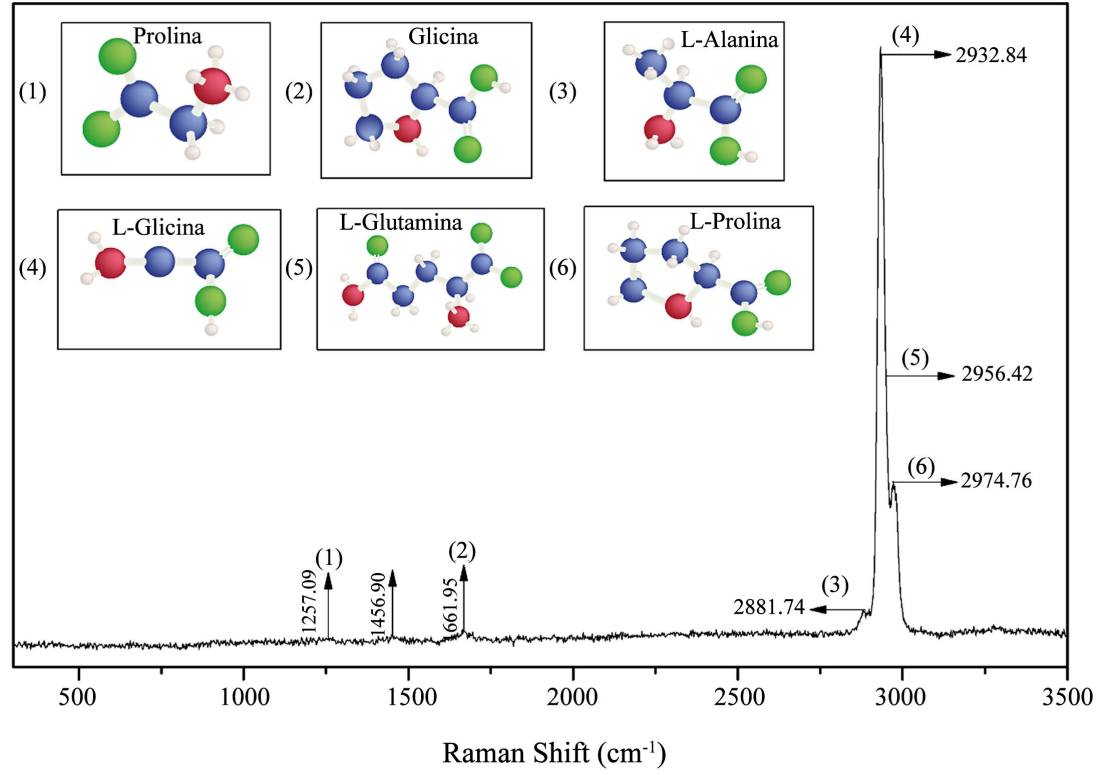

Figure 4. Raman spectra of a spider web fiber of the genus Gasteracantha at 100× magnification.

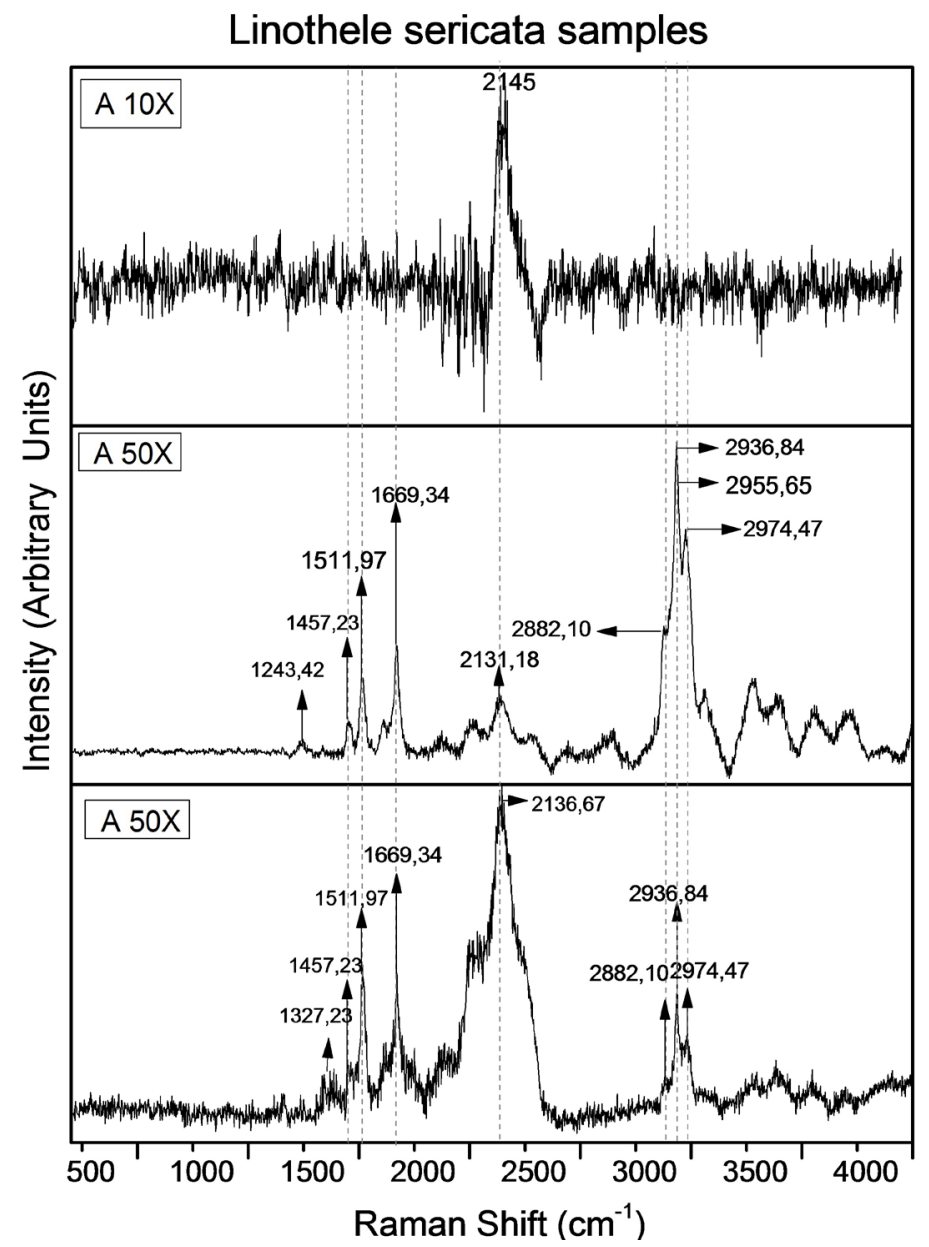

Figure 5. Raman spectra of the spider web of the genus Linothele sericata at $10 \times$ and $50 \times$ magnification. 
Table 4. Composition of the spider web of the genus Gasteracantha.

\begin{tabular}{cc}
\hline Raman Shift $\left(\mathrm{cm}^{-1}\right)$ & Attributions \\
\hline 1533.33 & Amide II \\
2155 & Isonitrile R-N-C bond \\
3416.67 & Amide A \\
\hline
\end{tabular}

Table 5. Composition of the spider web of the genus Gasteracantha.

\begin{tabular}{cc}
\hline Raman Shift $\left(\mathrm{cm}^{-1}\right)$ & Attributions \\
\hline 2871.84 & L-glycine \\
2936.84 & L-alanine \\
2955.65 & L-glutamine \\
2974.47 & L-proline \\
3056.57 & Secondary amines \\
\hline
\end{tabular}

Table 6. Composition of the spider web of the genus Linothele sericata.

\begin{tabular}{cc}
\hline Raman Shift $\left(\mathrm{cm}^{-1}\right)$ & Attributions \\
1243.42 & Amide III \\
1327.23 & $\mathrm{CH}_{2}$ formation \\
1457.23 & $\mathrm{CH}_{2}$ deformation \\
1511.97 & Amide II \\
1650.52 & Asymmetric deformation of $\mathrm{NH}_{3}$ \\
1669.34 & Amide I \\
2131.18 & Isonitrile R-N-C bond \\
2882.10 & L-glycine \\
2936.84 & L-alanine \\
2955.65 & L-glutamine \\
2974.47 & L-proline \\
& \\
\hline
\end{tabular}

to the genus of the spider, the spider fiber composition depends on its functionality and allows the material to have such particular characteristics. In the genus Araneus, there are $20 \mu \mathrm{m}$ thick fibers, with villi in each of these, and with axial threads with an approximate size of $1 \mu \mathrm{m}$. The spider web threads are composed of a protective layer mainly composed of amides, alanine, and glycine. The characteristic peaks located between 1245 and $2975 \mathrm{~cm}^{-1}$ are assigned to amide II and the amino acids glycine, alanine, L-glutamine, and L-proline. The inner cylinder formed by the threads consists mainly of L-alanine, L-glutamine and L-proline. The fibrils surrounding the axial fibers consist mainly of amide II $\left(1533 \mathrm{~cm}^{-1}\right)$, which allows adhesion between the thread and the surfaces onto which the spider weaves the web. In the genus Gasteracantha, characteristic peaks of the predominant amino acids in the spider web can be observed and are 
located between 2871 and $2975 \mathrm{~cm}^{-1}$. In this particular case, the measurement of the fiber cover lacks certain elements that appear in the inside of the spider web threads, such as L-glycine, which is responsible for synthesizing substances. An accumulation of silk is observed, produced by the spider as a protective mechanism, where peaks can be seen between 1257.09 and $2975 \mathrm{~cm}^{-1}$, which belong to the amino acids and amides present. In the genus Linothele sericata, the analysis of the fibers shows a very hairy or fibrous silk type. There exhibit an irregular formation due to the functionality of such structures or spider webs, which are built in shelters created close to the ground and therefore require many hairs in each of the threads for the prey to adhere easily to the spider web. On the surface of this spider web, the peak located at $2145 \mathrm{~cm}^{-1}$ is clearly detected and is assigned to isonitriles with RNC bonds, arising from the outside of the fiber. Within this fiber, there are other peaks characteristic of spider silk associated with amides and L-alanine, L-glutamine, and L-proline.

\section{Acknowledgements}

CVH gratefully acknowledges DIMA-Universidad Nacional de Colombia-Manizales for providing financial assistance for this study. Financial support for this study was provided by "Fondo Nacional de Financiamiento para la Ciencia, la Tecnología y la Innovación, Fondo Francisco José de Caldas" (COLCIENCIAS) under Project No. 116-2016 “Detección de ADN genómico usando microestructuras de $\mathrm{ZnO}$ mediante la Espectroscopia Raman como método de sondeo". CVH would like to thank F. N. Rosero for providing the samples and valuable comments and suggestions that improved this manuscript.

\section{Conflicts of Interest}

The authors declare no conflicts of interest regarding the publication of this paper.

\section{References}

[1] Arnaldez, R. (1971). La ciencia antigua y medieval (de los orígenes a 1450) [Ancient and Medieval Science (from the Origins to 1450)]. Ed. Destino, Barcelona.

[2] Berenbaum, M.R. (1995) Spin Control. The Sciences, 35, 13-15. https://doi.org/10.1002/j.2326-1951.1995.tb03193.x

[3] Miranda, J.A. (2015) Caracterizacion de las propiedades dinamicas de la seda de araña. Tesis Doctoral, Universidad politecnica de Madrid.

http://oa.upm.es/39341/1/JORGE_HERNAN_ALENCASTRE_MIRANDA.pdf

[4] Gosline, J.M., Guerette, P.A., Ortlepp, C.S. and Savage, K.N. (1999) The Mechanical Design of Spider Silks: From Fibroin Sequence to Mechanical Function. The Journal of Experimental Biology, 202, 3295-3303. http://jeb.biologists.org/content/202/23/3295.long

[5] http://www.ojocientifico.com/4671/como-hacen-las-aranas-su-telarana

[6] Pekár, S., Coddington, J.A. and Blackledge, T.A. (2011) Evolution of Stenophagy in Spiders (Araneae): Evidence Based on the Comparative Analysis of Spider Diets. 
Evolution, 66, 776-806. https://doi.org/10.1111/j.1558-5646.2011.01471.x

[7] Foelix, R.F. (1996) Biology of Spiders. Segunda Edición (Second Edition), Oxford University Press, Georg Thieme Verlag, New York, Oxford.

[8] Chemistry of Spider Silks. 1 April 2010. https://zh.scribd.com/doc/29937343/La-quimica-de-las-telas-de-arana

[9] Amoabediny, G., Salehi-Nik, N. and Heli, B. (2011) The Role of Biodegradable Engineered Scaffold in Tissue Engineering. In: Pignatello, R., Ed., Biomaterials Science and Engineering, InTech, 153-172.

[10] Chris, B. (2018) usos humanos de la telaraña [human use of spider silks].

[11] Foelix, R.F. (2011) Biology of Spiders. 3rd Edition, Oxford University Press, Oxford.

[12] Toft, S. (1999) Prey Choice and Spider Fitness. The Journal of Arachnology, 27, 301-307.

[13] Blackledge, T.A. (2012) Spider Silk: A Brief Review and Prospectus on Research Linking Biomechanics and Ecology in Draglines and Orb Webs. The Journal of Arachnology, 40, 1-12. https://doi.org/10.1636/M11-67.1

[14] Simon, E. (1884) Arachnides observes a Miranda de Ebro au mois d'aoùt [observed in Miranda de Ebro in August, 1883]. Anales de la Sociedad Española de Historia Natural, 13, 113-129.

[15] Dippenaar-Schoeman, A.S. and Jocqué, R. (2006) Spider Families of the World. Royal Museum for Central Africa, $336 \mathrm{p}$.

[16] Cardoso, P., Pekar, S., Jocque, R. and Coddington, J.A. (2011) Global Patterns of Guild Composition and Functional Diversity of Spiders. PLOS ONE, 6, e21710. https://doi.org/10.1371/journal.pone.0021710

[17] Zschokke, S. (2002) Ultraviolet Reflectance of Spiders and Their Webs. The Journal of Arachnology, 30, 246-254. https://doi.org/10.1636/0161-8202(2002)030[0246:UROSAW]2.0.CO;2

[18] Eberhard, W.E. (2008) Araneus expletus (Araneae, Araneidae): Another Stabilimentum That Does Not Function to Attract Prey. The Journal of Arachnology, 36, 191-194. https://doi.org/10.1636/St07-35SC.1

[19] Gregory, B.M. (1989) Field Observations of Gasteracantha cancriformes (Araneae, Araneidae) in a Florida Mangrove Stand. The Journal of Arachnology, 17, 119.

[20] Eberhard, W.E. (2006) Stabilimenta of Philoponella vicina (Araneae: Uloboridae) and Gasteracantha cancriformis (Araneae: Araneidae): Evidence against a Prey Attractant Function. Biotropica, 39, 216-220. https://doi.org/10.1111/j.1744-7429.2006.00254.x

[21] Jaffe, R., Eberhard, W., De Angelo, C., Eusse, D.,Gutierrez, A., Quijas, S., Rodrıguez, A. and Rodriguez, M. (2006) Caution, Webs in the Way! Possible Functions of Silk Stabilimenta in Gasteracantha cancriformes (Araneae, Araneidae). The Journal of Arachnology, 34, 448-455. https://doi.org/10.1636/S04-28.1

[22] Dippenaar-Schoeman, A.S. (2002) Baboon and Trapdoor Spiders of Southern Africa: An Identification Manual. Plant Protection Research Institute, Pretoria, 135 p.

[23] Blackledge, T.A. and Hayashi, C.Y. (2006) Unraveling the Mechanical Properties of Composite Silk Threads Spun by Cribellate Orb-Weaving Spiders. Journal of Experimental Biology, 209, 3131-3140. https://doi.org/10.1242/jeb.02327

[24] Trujillo, A.M.S. and Polo, R.Z. (2013) Analysis of the Topology of the Spider Silks on Their Behavior after Impact.

[25] Ortlepp, C. and Gosline, J.M. (2008) The Scaling of Safety Factor in Spider Drag- 
lines. The Journal of Experimental Biology, 211, 2832-2840.

https://doi.org/10.1242/jeb.014191

[26] Hagn, F., Eisoldt, L., Hardy, J.G., Vendrely, C., Coles, M., Scheibel, T. and Kessler, H. (2010) A Conserved Spider Silk Domain Acts as a Molecular Switch That Controls Fibre Assembly. Nature, 465, 236-242. https://doi.org/10.1038/nature08936

[27] Sapede, D. (2006) Contributions à la compréhension de la structure et de la dynamique hiérarchiques du fil de traîne de l'araignée. $\mathrm{PhD}$ Thesis, Université Joseph Fourier, Grenoble.

[28] Wiley, C. and Long, D.A. (2002) The Raman Effect. A Unified Treatment of the Theory of Raman Scattering by Molecules. 